\title{
COMPLEXE ACIDE TÉICHOIQUE-MUCOPEPTIDE DES PAROIS CELLLLAIRES DE BACILLUS MEGATERIUM KM
}

\author{
J. M. GHUYSEN \\ Université de Liège, Sevvice de Bacteriologie, Liège (Belgique) \\ (Reçu le 25 novembre Ig60)
}

\section{SUMMARY}

Teichoic acid-mucopeptide complex of cell walls of Bacillus megaterium KM

Walls of a batch of Bacillus megaterium KM contain a polyol phosphate compound which, in contrast with BADDiLEy's teichoic acids, is not extracted by cold trichloroacetic acid.

It has been isolated by paper electrorheophoresis from the non-dialysable fraction obtained after incubation of the walls by lysozyme.

Owing to the chemical analysis, it is associated with mucopeptide residues and the whole complex represents $40 \%$, dry weight, of the walls.

The degradation of this complex by two Streptomyces enzymes enables the identification of three fragments: a teichoic fragment of polyol phosphate, glucose and $\mathrm{N}$ acetylglucosamine; a mucopeptide fragment of amino acids and $\mathrm{N}$-acetylmuramic acid; a disaccharide fragment $6-\mathrm{O}-\beta-\mathrm{N}$-acetylglucosaminyl-N-acetyl-muramic acid. It is believed that the latter represents an unit of a poly-N-acetylhexosamine backbone of the basal mucopeptide of the wall.

: The teichoic fragment is liberated from the whole complex under the action of both Streptomyces enzymic preparations FI or F2B. It can also be obtained by incubating directly the walls with each of those preparations. The disaccharide fragment is liberated under the action of the $\mathrm{F}_{2} \mathrm{~B}$ amidase.

Approx. $6 \%$, dry weight, of the walls consist of glucose (probably a polyglucose) non associated with the teichoic acid-mucopeptide complex.

$\mathrm{N}$-acetylmuramic acid and various oligosaccharides consisting of $\mathrm{N}$-acetylglucosamine alone or of both $\mathrm{N}$-acetylglucosamine and $\mathrm{N}$-acetylmuramic acid, give, on paper, a pink coloration with the diphenylamine-trichloroacetic reagent which allows them to be distinguished from $\mathrm{N}$-acetylglucosamine.

\section{INTRODUCTION}

Les acides téichoiques que BADDILEY et al. ${ }^{1}$ ont isolés à partir d'extraits trichloracétiques des parois cellulaires de Lactobacillus arabinosus, de Bacillus subtilis et Staphylococcus aureus sont des polymères de phosphates de polyol dont certaines fonctions hydroxyles sont condensées avec une molécule de glucose ou une molécule de $\mathrm{N}$-acétylglucosamine, elles-mêmes associées à un résidu D-alanyle par une liaison $\alpha$-amino ester. L'acide téichoique extrait des parois de $B$. subtilis a été plus parti- 
culièrement étudié ${ }^{2}$ Il est constitué d'une chaîne de neuf unités D-alanyle- $4-\mathrm{O}-\beta$ D-gluco-pyranosyle-D-ribitol-5-phosphate.

Ces acides téichoiques extraits par l'acide trichloracétique froid seraient associés au reste de la paroi bactérienne par des liaisons ioniques. Cependant, la quantité d'acide téichoique extraite est toujours inférieure à celle prévue par le contenu en phosphore des parois. Selon les bactéries examinées et les conditions dans lesquelles celles-ci ont été cultivées, le rendement de l'extraction varie de o à $80 \%$. Ainsi, Armstrong et al. ${ }^{2}$ ont observé que l'extrait trichloracétique des cellules de B. subtilis cultivées en présence de quantité assez élevée de glucose $(2 \%)$ (au lieu de peptone$\mathrm{NaCl})$ ne contient pas d'acide téichoique.

De même, il a été observé que la totalité des acids téichoiques d'une préparation de parois cellulaires de Bacillus megaterium KM résiste à l'extraction par une solution d'acide trichloracétique à $10 \%\left(0^{\circ}\right)$. La présente recherche a eu pour objet la constitution de ces acides téichoiques et la façon dont ils s'intègrent dans la structure des parois. Elle a consisté dans la séparation et l'analyse d'un certain nombre de produits de dégradation, obtenus par l'hydrolyse partielle, enzymatique et chimique, des parois de B. megaterium KM.

\section{MATÉRIEL ET MÉTHODES}

\section{Parois cellulaires}

B. megaterium KM a été cultivé en milieu peptoné $5 \%$, à $25^{\circ}$, avec aération forcée. Les parois ont été préparées par le procédé de SAITON ET HORNE ${ }^{3}$.

\section{Enzymes}

Outre le lysozyme du blanc d'oeuf (Armour), deux autres préparations enzymatiques - FI et F2B - obtenues par fractionnement du filtrat de culture d'un Streptomyces $^{4-8}$ ont été utilisées. Les conditions d'incubation à $37^{\circ}$ ont été: Enzyme/Substrat $=0.0 \mathrm{I}$ pour FI et le lysozyme; 0.02 pour F2B; tampon acétate ammonique, $0.05 \mathrm{M}$ pour Fi et le lysozyme; $0.005 M$ pour F2B.

\section{Chromatographie et électrorhéophorèse}

Les chromatographies ont été réalisées sur papier Whatman No I et les électrorhéophorèses sur papier Whatman $3 \mathrm{MM}$, au moyen de l'appareil Electrorhéophor Pleuger (Anvers, Belgique), d'un cadre utile de $40 \mathrm{~cm} / 40 \mathrm{~cm}$ et aux pH 2.5 (acide acétique o.I $N$ ), 4 (acide acétique-pyridine-eau $(9: 2: 1000, v / \mathrm{v} / \mathrm{v})$ ) et 5.5 (acide (acide acétique-pyridine-eau $(2: 4:$ I000, v/v/v)).

\section{Identifucations sur papier}

Les acides aminés et les hexosamines ont été détectés par la riinhydrine $(0.2 \%$ en acétone), les hexosamines par le réactif de Partridge et WEstalL ${ }^{9}$, les N-acétylhexosamines par celui de SALTON ${ }^{10}$, les sucres par le phthalate d'aniline et le glucose par la glucose oxydase (Worthington Bioch. Corp.) ${ }^{21}$.

Le réactif de Hovgr et al. ${ }^{11}$ ( $2 \%$ diphénylamine en $n$-butanol-methanol( ( $\mathrm{I}: \mathrm{I}$, $\mathrm{v} / \mathrm{v}$ ) contenant $5 \%$ d'acide trichloracétique) (chauffage Io min à Ioo ${ }^{\circ}$ ) a également été utilisé. Il a permis de différencier l'acide $\mathrm{N}$-acétylmuramique (coloration rose) et la $\mathrm{N}$-acétylglucosamine (coloration gris-verdâtre). Par contre, les disaccharides $\beta(\mathrm{I}-4)$ di-N-acétylglucosamine ou $\beta(\mathrm{I}-6) \mathrm{N}$-acétylglucosaminyle-acide $\mathrm{N}$-acétylmuramique (AG-AAM) ainsi que leurs dimères respectifs, le $\beta(I-4)$ tétra-N-acétyl- 
glucosamine et le tétrasaccharide $\mathrm{AG}-\mathrm{AAM}-\mathrm{AG}-\mathrm{AAM}{ }^{7}$ sont tous, sur papier, colorés en rose par ce réactif. En particulier, ro $\mu \mathrm{g}$ du disaccharide AG-AAM sont encore décelables après chromatographie en $n$-butanol-acide acétique-eau (3:I:I, v/v/v). Par rapport à ce standard, la sensibilité de la méthode est comparable à celle de SALTON $^{10}$ à la $p$-diméthylaminobenzaldéhyde. Le mécanisme de la réaction n'a pas été étudié. On sait cependant que la déacétylation du groupe aminé de l'acide $\mathrm{N}$-acétylmuramique supprime la coloration.

Les polyols ont été détectés par le réactif de Schiff après oxydation periodique en utilisant soit le procédé de Buchanan et al.12, soit, le plus souvent, les réactifs proposés par la firme Spinco ${ }^{13}$ pour la révélation des glycoprotéines du sérum. Dans ce dernier cas, on a opéré comme suit: Les papiers sont vaporisés par la solution alcoolique d'acide periodique, maintenus ro min dans un courant d'air, suspendus dans une atmosphère de $\mathrm{SO}_{2}$ (destruction de l'excès de réactif), vaporisés par la solution de fuchsine réduite (Basic Fuchsin Dye Spinco ou Fuchsin Diamant-, Grose Krisralle. Lot I538. E. Merck), puis maintenus dans un courant d'air (20-40 min), enfin réintroduits en atmosphère de $\mathrm{SO}_{2}$. Le ribitol et le mannitol apparaissent, après quelques minutes, colorés en violet pourpre. L'anhydroribitol, obtenu par hydrolyse acide du ribitol, apparaît en bleu de même qu'un second produit de décomposition, le dianhydroribitol probablement ${ }^{14}$. L'hydrolyse acide du mannitol donne naissance à deux produits de décomposition: l'un apparait immédiatement en jaune virant plus tard au vert bleu, l'autre se révèle plus tardivement coloré en bleu.

\section{Dosages}

Les acides aminés ont été dosés (après hydrolyse de l'échantillon par $\mathrm{HCl} 6 \mathrm{~N}$, I6 h) en extrayant des chromatogrammes, les taches ninhydrine positives par le mélange acétone-eau $(3: \mathrm{I}, \mathrm{v} / \mathrm{v})$ et en mesurant à $570 \mathrm{~m} \mu$ la densité optique des solutions obtenues. Le phosphore a été dosé (après hydrolyse perchlorique) par le procédé de $\mathrm{KING}^{15}$; les hexosamines (après hydrolyse par $\mathrm{HCl} 6 \mathrm{~N}$, I6 h) par le procédé de Neuhauer eT LeTzRING ${ }^{\mathbf{1 6}}$ en utilisant le rapport $^{\mathbf{5}}$ densité optique glucosamine/ densité optique acide muramique $=2.30$; le disaccharide AG-AAM (sans hydrolyse préalable) par le procédé de Reissig et al. ${ }^{17}$ modifié selon GHUySEN ET SALToN ${ }^{5}$.

Pour le dosage des groupes hydroxyles, on chauffe à $100^{\circ}$, pendant $3 \mathrm{~h}$, en ampoules scellées, l'échantillon sec en présence du réactif d'acétylation de WiLson ET Hughes $^{18}$ (I mg/ml de mélange: anhydride acétique-pyridine $(24: 235, \mathrm{v} / \mathrm{v})$ ). Les solutions sont ensuite évaporées sous vide et les groupes $\mathrm{O}$-acétyles dosés par le test d'Hestrin en utilisant le procédé de MCCombe ET MCCREADY ${ }^{19}$ adapté comme suit: les résidus secs, dissous dans $0.7 \mathrm{ml}$ d'eau sont traités pendant $\mathrm{I} 5 \mathrm{~min}$ en bain de glace, par $0.28 \mathrm{ml} \mathrm{du}$ mélange $\mathrm{NaOH}$-hydroxylamine $\cdot \mathrm{HCl}$. On ajoute ensuite $0.7 \mathrm{ml}$ de la solution d'acide perchlorique en méthanol puis $1.82 \mathrm{ml}$ de la solution diluée de perchlorate de fer. Les densités optique sont mesurées à $520 \mathrm{~m} \mu$. Le procédé a été appliqué au ribitol, au mannitol et au glycérophosphate de soude utilisés comme substances de référence. La Fig. I montre que la densité optique à $520 \mathrm{~m} \mu$ des solutions finales ne dépend que du nombre de fonctions hydroxyles mises en oeuvre quelle que soit la substance utilisée pour le test.

Le glucose a été dosé soit par la méthode à la glucose oxydase (après hydrolyse par $\mathrm{HCl} 2 \mathrm{~N}, 3 \mathrm{~h}$ ), soit par la réaction de Dische (sans hydrolyse préalable) modifiée comme suit: à $\mathbf{I} \mathrm{ml}$ de la solution (ou suspension de parois cellulaires) à tester, on 
ajoute $3 \mathrm{ml}$ d'une solution à $0.75 \%$ de diphénylamine dans un mélange acide acétiqueacide sulfurique $(d$, I.8)-acide chlorhydrique $(d, I . I 9)(9: I: 5, v / v / v)$ et on chauffe $\mathrm{I} h$ au bain-marie bouillant. Après un repos d'une nuit, la densité optique de la solution est mesurée à 525 et $625 \mathrm{~m} \mu$ et on se rapporte à une courbe d'étalonnage obtenue à partir de quantités connues de glucose.

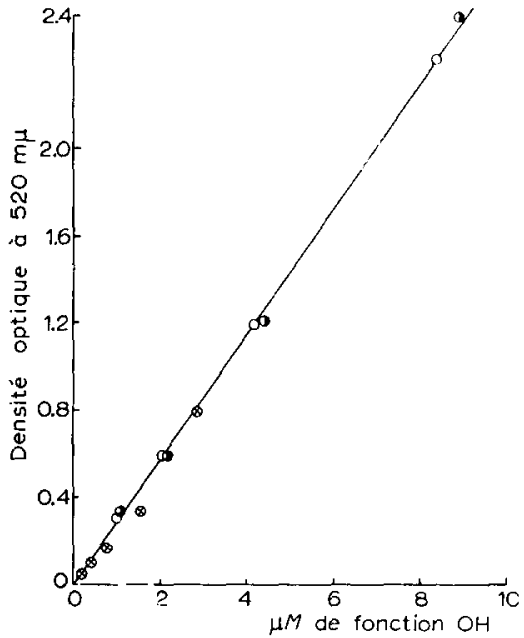

Fig. 1.

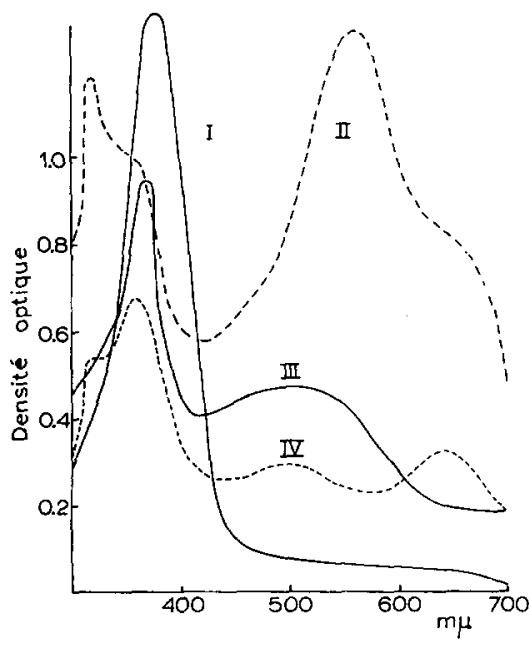

Fig. 3.

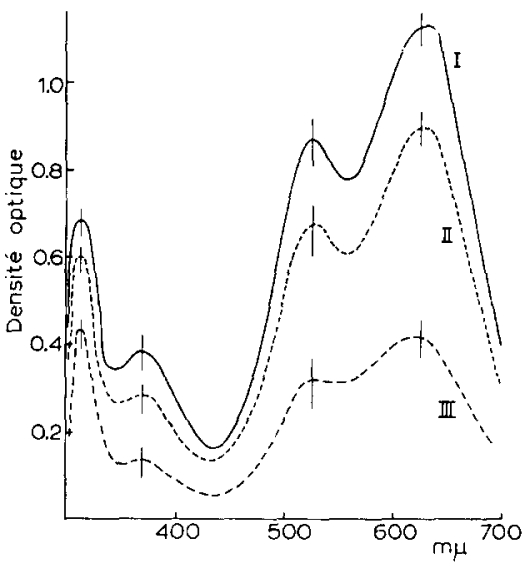

Fig. 2.

Fig. 1. Dosage des fonctions hydroxyles du ribitol, du mannitol et du g]ycérophosphate sodique, par appliplication du test d'Hestrin après acétylation en anhydride acétique-pyridine. $-(\mathbf{D i b i t o l} ; 0-0$, mannitol; $Q-\otimes$, glycérophosphate sodique.

Fig. 2. Spectres d'absorption du glucose et de fractions obtenues par traitement enzymatique des parois cellulaires de $B$. megaterium KM, après réaction avec la diphénylamine. 1. glucose, Ioo $\mu \mathrm{g}$; II, fraction non dialysable obtenue en incubant les parois cellulaires par le Jysozyme (fraction KM. Lys NI) $500 \mu \mathrm{g}$; III, complexe Schiff positif, isolé de la fraction non dialysable obtenue en incubant les parois cellulaires par $F_{2} B$ (fraction $K M \cdot F 2 B \cdot N I$ ) Ioo $\mu \mathrm{g}$. Les spectres ont été obtenus après un chauffage au BM bouillant de 60 min et repos d'une nuit à la température du laboratoire.

Fig. 3. Spectres d'absorption de divers hydrates de carbone après réaction avec la diphenylamine. 1, rhamnose $200 \mu \mathrm{g}$; II, anhydro sédoheptulose $200 \mu \mathrm{g}$; III, acide galacturonique $400 \mu \mathrm{g}$; IV, ribose $200 \mu \mathrm{g}$. Les spectres ont été obtenus après un chauffage au BM bouillant de $30 \mathrm{~min}$ et repos d'une nuit à la température du laboratoire.

La méthode chimique donne des résultats supérieurs de 30 à $50 \%$ à ceux obtenus par la méthode enzymatique. Or, au cours de l'hydrolyse acide qui précède l'application du test enzymatique, une certaine quantité de glucose libéré au début du chauffage peut être ultérieurement détruite. De plus, une chromatographie du matériel obtenu après $3 \mathrm{~h}$ d'hydrolyse a montré qu'une certaine quantité de glucose était 
toujours engagée dans différents complexes et échappait par conséquent au dosage.

Par contre, la méthode chimique peut ne pas être spécifique. Tous les hexoses donnent une coloration bleue intense dont le spectre est identique à celui donné par le glucose (Fig. 2, courbe I). La sensibilité varie cependant selon la nature de l'hexose, dans l'ordre décroissant suivant: fructose $>$ sorbose $>$ mannose $>$ glucose $>$ galactose $>$. Pentoses, méthylpentoses, heptoses et acides hexuroniques donnent des spectres différents (Fig. 3), avec des maxima aux longueurs d'onde suivantes: 360 , 580 et $640 \mathrm{~m} \mu$ pour les pentoses (sensibilité : xylose et ribose $>$ arabinose); $375 \mathrm{~m} \mu$ pour les méthylpentoses (sensibilité: rhamnose $>$ fucose); 320 et $560 \mathrm{~m} \mu$ pour le sedoheptulose; 365 et 490 à $530 \mathrm{~m} \mu$ pour les acides hexuroniques (sensibilité: acide galacturonique $>$ acide glucuronique). La $\mathrm{N}$-acétylglucosamine, l'acide $\mathrm{N}$-acétylmuramique, leurs hexosamines respectives, le ribitol et le mannitol donnent des réactions négatives (de Ioo à $400 \mu \mathrm{g}$ ).

Dans le cas des parois de B. megaterium KM, la méthode chimique est cependant préférable à celle qui utilise la glucose oxydase. En effet, le glucose est le seul sucre non aminé qu'on y décèle. De plus, en appliquarit la réaction de Dische modifiée aux diverses préparations solubles dérivant des parois de $B$. megaterium KM, les spectres des solutions obtenues sont identiques à celui donné par une solution de glucose (Fig. 2). Enfin, les densités optique à 525 et $625 \mathrm{~m} \mu$ d'un mélange (glucose + préparation dérivant de parois) est la somme des densités optiques individuelles.

La méthode modifiée de Dische n'a cependant pu être appliquée aux fractions purifiées par électrorhéophorèse sur papier Whatman 3 MM que lorsque la quantité extraite à partir de $2 \mathrm{~cm}^{2}$ environ de papier donnait une solution dont la densité optique à $625 \mathrm{~m} \mu$ était au moins égale à o.2. En effet, un extrait aqueux de $2,4 \mathrm{et} 6 \mathrm{~cm}^{2}$ de ce papier a donné, après réaction dans les conditions décrites, des solutions dont les densités optique à $625 \mathrm{~m} \mu$ sont respectivement de $0.020,0.070$ et 0.170 .

\section{RÉSULTATS EXPÉRIMENTAUX}

\section{Extraction des parois cellulaires de B. megaterium $K M$ par l'acide trichloracétique}

La technique utilisée par BADDILEY pour l'extraction des acides téichoiques a été appliquée à I g de parois de B. megaterium KM. Celles-ci ont été traitées, à $0^{\circ}$, pendant $24 \mathrm{~h}$ par une solution à ro \% d'acide trichloracétique (30 ml). L'extraction a été répétée deux fois et les extraits réunis ont été additionnés par 2 volumes d'acétone froid. Après un repos de $48 \mathrm{~h}$ à $0^{\circ}$, aucurie substance insoluble n'est apparue. De plus, la teneur des parois en phosphore n'a pas été modifiée par ce traitement. Exprimée par poids sec de parois, elle était égale à $0.556 \%$ avant traitement et à $0.567 \%$ après traitement.

\section{Digestion enzymatique des parois cellulaires de B. megaterium $K M$}

Les parois cellulaires de $B$. megaterium $\mathrm{KM}$ ne sont pas également sensibles au lysozyme, à $\mathrm{Fr}$ et à $\mathrm{F} 2 \mathrm{~B}$. A $37^{\circ}$, le trouble de leurs suspensions (I $\mathrm{mg}$ poids $\mathrm{sec} / \mathrm{ml}$ ) est réduit à $50 \%$ de sa valeur initiale en $20 \mathrm{~min}$ par $50 \mu \mathrm{g} / \mathrm{ml}$ de lysozyme ou $5 \mu \mathrm{g} / \mathrm{ml}$ de FI. Une réduction identique est obtenue par Io $\mu \mathrm{g} / \mathrm{ml}$ de $\mathrm{F}_{2} \mathrm{~B}$ en $\mathrm{Io} \mathrm{h}$.

Ces vitesses de clarification ne traduisent cependant pas le degré de dégradation des parois cellulaires traitées par chacun des enzymes. La dégradation peut être 
évaluée par la quantité de matériel non dialysable laissé inattaqué après une incubation de $18 \mathrm{~h}$. Le Tableau I montre que l'action dégradante du lysozyme, de FI et de $\mathrm{F}_{2} \mathrm{~B}$ va respectivement croissant. En incubant successivement au moyen des trois préparations enzymatiques, d'abord les parois cellulaires elles-mêmes puis les diverses fractions non dialysables qui en dérivent, celle finalement obtenue représente environ $37 \%$ en poids des parois initiales, quel que soit l'ordre selon lequel les enzymes ont été utilisés. Quelques rendements de ces diverses incubations sont donnés dans le Tableau I. Si l'ordre d'utilisation des enzymes est d'abord le lysozyme, puis Fi et enfin F2B, il est particulièrement évident qu'un enzyme donné n'a pas détruit le substrat sensible à l'enzyme utilisé immédiatement après lui et que ce substrat est chaque fois contenu dans la fraction non dialysable.

\section{TABLEAU I}

RENDEMENTS OBTENUS EN INCUBANT LES PAROIS CELLULAIRES DE $B$. megaterium KM PAR LE LYSOZYME, $F_{1}$ ET $F_{2} B$, UTILISÉS ISOLÉMENT OU SUCCESSIVEMENT

D, fraction dialysable; ND, fiaction non dialysable. Les rendements sont exprimés en \%, poids sec, des parois cellulaires originales.

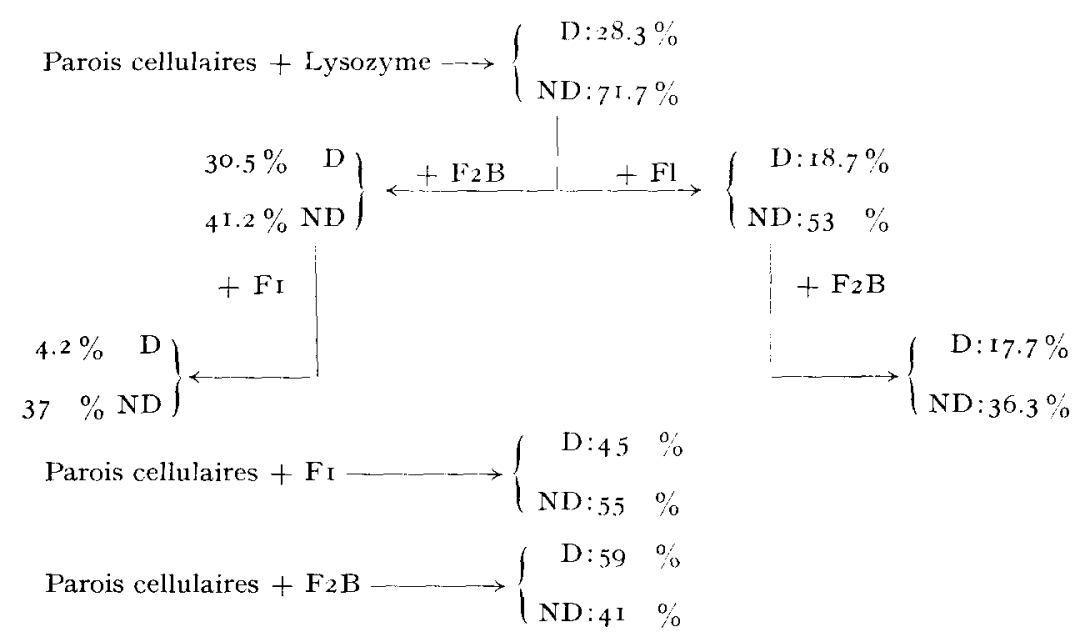

Les fractions dialysables obtenues après ces hydrolyses enzymatiques, isolées ou successives, ont été analysées par chromatographie bi-dimensionnelle en pyridine-eau $(8: 2, v / v)$ et $n$-butanol-acide acétique-eau $(3: I: I, v / v / v)$. Ces fractions contiennent soit des complexes de $\mathrm{N}$-acétylhexosamines, en particulier le disaccharide AG-AAM (après incubation avec le lysozyme ou la préparation $\mathrm{FI}$ ), soit des peptides et de l'alanine libre (après incubation avec $F_{I}$ ou $F_{2} B$ ), mais sont toujours dépourvus de phosphates de polyol. Au contraire, ceux-ci ont chaque fois été décelés dans les diverses fractions non dialysables. Ces tractions non dialysables on été désignées de la façon suivante; exemple: $\mathrm{KM} \cdot \mathrm{Lys} \cdot \mathrm{ND} ; \mathrm{F}_{\mathrm{I}} \cdot \mathrm{ND} ; \mathrm{F}_{2} \mathrm{~B} \cdot \mathrm{ND}$ est la fraction non dialysable obtenue en ayant incubé avec $\mathrm{F}_{2} \mathrm{~B}$ la fraction $\mathrm{KM} \cdot \mathrm{Lys} \cdot \mathrm{ND} ; \mathrm{FI} \cdot \mathrm{ND}$. Celle-ci désigne la fraction non dialysable obtenue par incubation avec FI de la fraction $\mathrm{KM} \cdot$ Lys $\cdot \mathrm{ND}$, qui, à son tour, représente la fraction non dialysable obtenue par incubation avec le lysozyme des parois cellulaires de B. megaterium KM. 


\section{Analyse électrorhéophorétique des fractions non dialysables}

Les diverses fractions non dialysables (Tableau I) ont été examinées par électrorhéophorèse et les complexes téichoiques qu'elles contiennent ont pu être facilement détectés grâce à leur sensibilité au réactif de Schiff après oxydation periodique.

La fraction KM. Lys. ND a été examinée aux $\mathrm{pH}$ 2.5, 4 et 5.5. Dans chaque cas, on a déterminé la position d'équilibre d'une substance à la fois décelable par la ninhydrine, le réactif des $\mathrm{N}$-acétylhexosamines ${ }^{10}$ et celui de Schiff après oxydation periodique (Fig. 4). Cette substance présente, aux trois $\mathrm{pH}$ examinés, un étalement assez considérable et est immédiatement précédée dans sa migration vers l'anode par une autre substance ou groupe de substances, insensibles au réactif de Schiff mais toujours décelables par les deux autres réactifs mentionnés. Malgré un certain chevauchement,

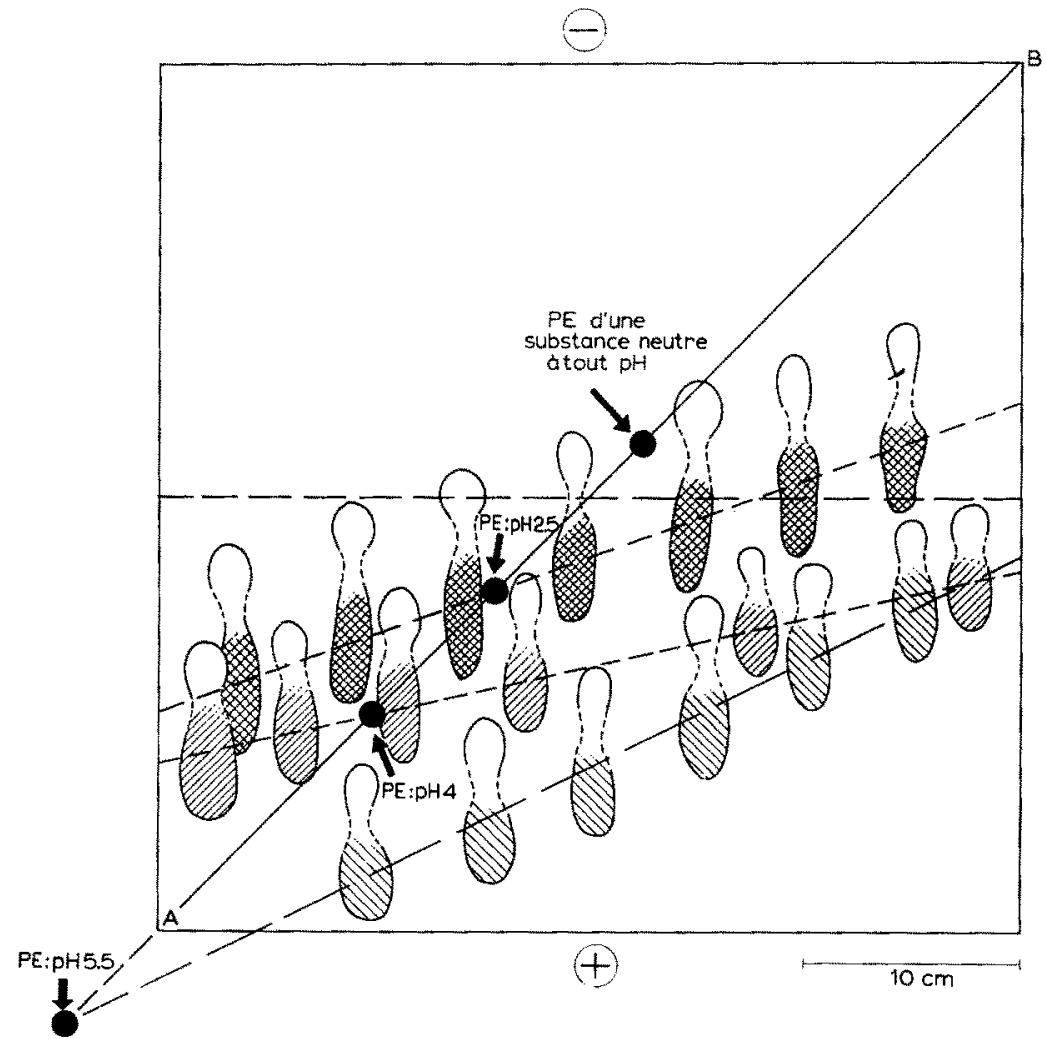

Fig. 4. Schéma des électrophorèses aux pH 2.5, 4 et 5.5 de la substance Schiff positive contenue dans la fraction non dialysable obtenue en traitant les parois cellulaires de $B$. megaterium KM par le lysozyme (fraction KM-Lys - ND). La fraction KM - Lys $\cdot \mathrm{ND}$ a été déposée selon la diagonale A B. Après électrorhéophorèse $(3 \mathrm{~h}, 20 \mathrm{~V} / \mathrm{cm})$, les papiers ont été révélés par la ninhydrine, le réactif des N-acétylhexosamines et le réactif de Schiff après oxydation periodique. Seules, les surfaces hachurées donnent une réaction positive avec ce dernier réactif. Le point d'intersection entre la diagonale $\mathrm{A} B$ et la droite tracée par le centre de chacune des surfaces hachurées est la position d'équilibre (PE), à un pH donné, de la substance Schiff positive. Par rapport à la position d'équilibre d'une substance neutre à tout $\mathrm{pH}$, la position d'équilibre de la substance Schiff positive se situe à 6.5 $\left(\mathrm{pH} \mathrm{2.5)}, 12\left(\mathrm{pH}_{4}\right)\right.$ et $27 \mathrm{~cm}\left(\mathrm{pH}_{5} .5\right)$ en direction de l'anode.

* Endroit du papier où la migration d'une substance donnée s'annule par suite d'un équilibre entre son transport dans un sens dâ à sa charge électrique et celui dans le sens opposé dù à l'évaporation du solvant du papier. 
la substance Schiff positive a été isolée de la fraction KM-Lys-ND par électrorhéophorèse à $\mathrm{pH} 4$ de $30 \mathrm{mg}$ de cette fraction (dépôt de $\mathrm{I} \mathrm{mg} / \mathrm{cm}$ au centre du papier, $20 \mathrm{~V} / \mathrm{cm}$ pendant $4 \mathrm{~h}$ ). Une bande de papier a été découpée de l'électrorhéophoréogramme de façon à exclure - avec une certaine perte de rendement - toute contamination par la substance Schiff négative. La substance Schiff positive ainsi purifiée s'est révélée homogène lors d'une nouvelle électrorhéophorèse (Fig. 5).
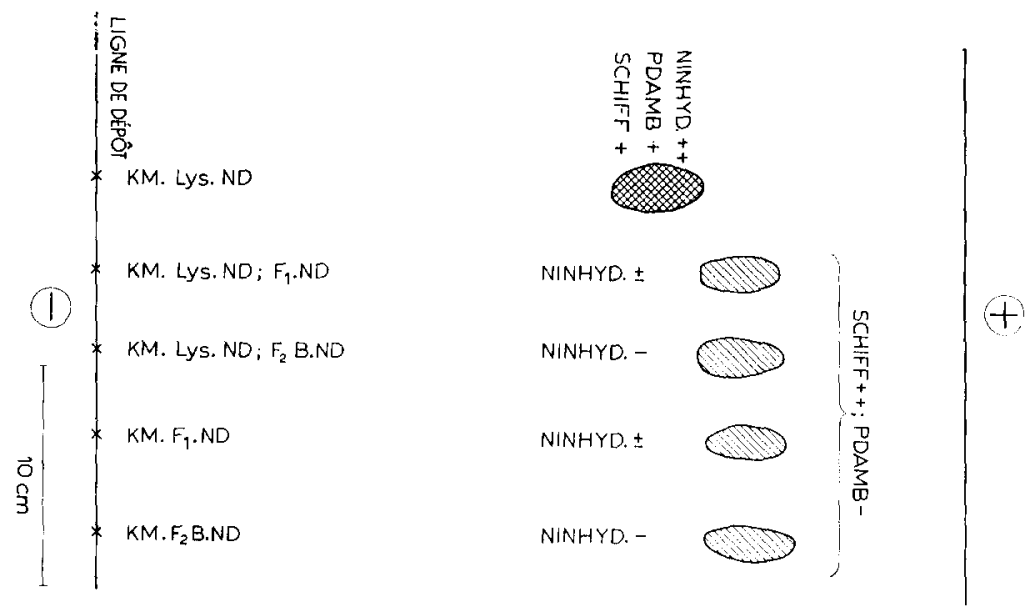

Fig. 5. Electrorhéophorèse $\left(\mathrm{pH}_{4}, 4 \mathrm{~h}, 20 \mathrm{~V} / \mathrm{cm}\right)$ de $200 \mu \mathrm{g}$ des complexes Schiff positifs, isolés à partir de diverses fractions non dialysables obtenues par traitement enzymatique des parois cellulaires de $B$. megaterium hM. Les électrophoréogrammes ont été réalisés en triple et respectivement révélés par la ninhydrine (ninhyd.), le réactif des $\mathrm{N}$-acétylhexosamines (PDAMB) et le réactif de Schiff après oxydation périodique.

Le même procédé de purification a été appliqué à toutes les fractions non dialysables reprises au Tableau I et a permis d'isoler la substance qui, dans chacune de ces fractions, est responsable de sa sensibilité au réactif de Schiff après oxydation periodique.

Les substances Schiff positive, isolées des fractions non dialysables qui, à un moment quelconque de leur préparation, ont subi une incubation soit avec FI soit avec $\mathrm{F}_{2} \mathrm{~B}$, ont toutes les mêmes caractéristiques et se distinguent de la substance Schiff positive isolée à partir de la fraction KM-Lys $\cdot N D$ (Fig. 5). En effet, elles sont chargées plus négativement que cette dernière, ne sont plus révélées par le réactif des $\mathrm{N}$-acétylhexosamines et ne sont que tròs peu sensibles à la ninhydrine.

\section{Nature du polyol responsable de la réaction de Schiff après oxydation poriodique}

$5 \mathrm{mg}$ de la fraction $\mathrm{KM} \cdot \mathrm{Lys} \cdot \mathrm{ND}$ et $2 \mathrm{mg}$ des substances Schiff positives isolées de la fraction $\mathrm{KM} \cdot \mathrm{F} 2 \mathrm{~B} \cdot \mathrm{ND}$, de la fraction $\mathrm{KM} \cdot \mathrm{Lys} \cdot \mathrm{ND} ; \mathrm{F}_{2} \mathrm{~B} \cdot \mathrm{ND}$ ou de la fraction $\mathrm{KM} \cdot \mathrm{Lys} \cdot \mathrm{ND} ; \mathrm{F}_{2} \mathrm{~B} \cdot \mathrm{ND} ; \mathrm{F}_{\mathrm{I}} \cdot \mathrm{ND}$ ont subi une hydrolyse acide ménagée $(2 \mathrm{mg} / \mathrm{ml}$; $\mathrm{HCl} 2 \mathrm{~N}$; $15 \mathrm{~min}$ à $100^{\circ}$ ) et l'hydrolysat lyophilisé a été chromatographié en butanol acétique. Le réactif de Schiff appliqué aux chromatogrammes n'a permis de mettre en évidence ni glycérol, ni ribitol, ni mannitol libres, ni aucun produit pouvant provenir de leur décomposition. Dans chaque cas cependant, une substance $\left(\boldsymbol{R}_{\boldsymbol{F}}\right.$ o.13) a été décelée. Au simple examen visuel des chromatogrammes, elle représente la majeure partie du matériel Schiff positif contenu dans l'hydrolysat. Son isolement a été réalisé 
de la façon suivante. roo mg de la préparation $\mathrm{KM} \cdot \mathrm{Lys} \cdot \mathrm{ND}$ ont été hydrolysés dans les conditions décrites ci-haut. Après élimination de l'acide par lyophilisation, le résidu a été repris dans Io $\mathrm{ml}$ d'eau et dialysé contre $50 \mathrm{ml}$ d'eau distillée. La dialyse a été renouvelée trois fois. Les fractions dialysables ont été réunies et lyophilisées. Le résidu sec a été soumis à une électrorhéophorèse à $\mathrm{pH} 2.5$ (dépôt sous forme d'une bande de $30 \mathrm{~cm}$ au centre du papier; $20 \mathrm{~V} / \mathrm{cm}$ pendant $3 \mathrm{~h}$ ) en même temps que du ribitol dont la révélation ultérieure a permis de situer la position de neutralité. Une bande de papier découpée dans l'électrorhẻophoréogramme selon le sens de la migration, révèle la présence à ce niveau de substances sensibles au réactif des $\mathrm{N}$-acétylhexosamines, à la glucose oxydase, ainsi qu'au réactif de Schiff après oxydation periodique. La zone de papier sensible à ce dernier réactif déborde cependant légèrement vers l'anode les zones révélées par les autres procédés. La bande de papier contenant l'ensemble des substances responsables des réactions précédentes, a été découpée de l'électrorhéophoréogramme et appliquée sur une nouvelle feuille de papier $3 \mathrm{MM}$, cette fois près de l'électrode négative. Après une nouvelle électrorhéophorèse à pH $5.5(20 \mathrm{~V} / \mathrm{cm}$ pendant $\mathbf{I}_{5} \mathrm{~min}$ ), les substances, neutres ou pratiquement neutres à $\mathrm{pH} \mathrm{2.5}$, se sont séparées en trois fractions ayant migré vers l'anode respectivement de I I cm (fraction neutre: $\mathrm{N}$ ), de $20 \mathrm{~cm}$ (fraction acide: A20) et de $30 \mathrm{~cm}$ (fraction acide: A30) (Tableau II).

TABLEAU II

FRACTIONNEMENT ÉLECTRORHÉOPHORÉTIQUE DE L'HYDROLYSAT ACIDE PARTIEL DE LA FRACTION KM·Lys ND

\begin{tabular}{cll}
\hline \multicolumn{1}{c}{ Comportement $\dot{\alpha} p H$} & Fraction \\
\hline 2.5 & \multicolumn{1}{c}{5.5} & \\
\hline Neutre & Neutre & $\mathrm{N}$ \\
Neutre & Acide & A 20 \\
Neutre & Très acide & A 30 \\
\hline
\end{tabular}

Seule cette dernière fraction A30 était décelable par le réactif de Schiff. Elle était de plus insensible à la ninhydrine et au réactif des $\mathrm{N}$-acétylhexosamines. Eluée de la bande de papier correspondante, elle s'est comportée au cours d'une chromatographie en butanol acétique comme étant composée d'une seule substance migrant avec un $R_{F}$ égal à o.I3. La fraction A3o a été analysée sans avoir subi de purifications ultérieures, avec pour résultat, une proportion phosphore/fonction hydroxyle/glucose/ hexosamine (exprimé sous forme de glucosamine)/acide aminé égale à I/3.I/o.033/ $0.007 / 0.000$.

Ces rapports indiquent que la fraction A3o est presque exclusivement constituée par du phosphate de polyol. Celui-ci pourrait vraisemblablement s'identifier au ribitol puisque le rapport $\mathrm{P} / \mathrm{OH}$ d'une chaîne de phosphates de ribitol (où les résidus de polyol sont unis par l'intermédiaire de liaisons phosphodiester) est compris entre $\mathrm{I} / 4 \mathrm{et}$ r/3 selon le degré de polymérisation.

La fraction A3o présente cependant plusieurs propriétés imprévues. Son ionisation est très réduite à $\mathrm{pH} \mathbf{2 . 5}$, ce qui exclut la présence d'un $\mathrm{OH}$ phosphorique primaire alors qu'une telle fonction semble être présente dans les complexes Schiff positifs isolés des diverses fractions non dialysables. En effet, ces complexes sont fortement chargés négativement à $\mathrm{pH} 2.5$ ainsi qu'en témoigne leur comportement électrorhéophorétique (Fig. 4). 
La fraction $\mathrm{A}_{30}$ ainsi que du ribitol et du mannitol ont été traités à roo ${ }^{\circ}$ soit par $\mathrm{HCl} 2 \mathrm{~N}$ pendant $3 \mathrm{~h}$ soit par $\mathrm{HCl} 6 \mathrm{~N}$ pendant $\mathrm{I} 6 \mathrm{~h}$ (ampoules scellées; $\mathrm{I} \mathrm{mg} / \mathrm{ml}$ ) puis chromatographiés en butanol-acétique après lyophilisation. La fraction A3o n'est pratiquement pas affectée par ces divers traitements acides et migre toujours de façon homogène avec un $R_{F}$ 0.I3. Une trace d'anhydroribitol $\left(R_{F} \quad 0.54\right)$ semble cependant avoir été formée lorsque l'hydrolyse a été effectuée en présence de $\mathrm{HCl} 6 \mathrm{~N}$ pendant I6 h. La proportion $\mathrm{P} / \mathrm{OH}$ a été redéterminée à partir de la fraction $\mathrm{A} 30$ ayant subi le même traitement et a été trouvée égale à $\mathrm{I} / 3.5$.

La fraction $\mathrm{A} 30$ est donc très stable aux traitements acides. On notera cependant qu'après hydrolyse acide des parois intactes de $B$. megaterium $\mathrm{KM}$ on ne décèle pas, non plus, de polyol libre ou un de ses produits de dégradation.

La structure de la fraction Azo reste donc à déterminer. Cependant, sa composition chimique globale montre que les complexes Schiff positifs isolés des fractions non dialysables obtenues après digestion enzymatique des parois de B. megaterium KM sont constitués, au moins partiellement, de phosphate de polyol. Le terme d'acide téichoique leur est donc applicable.

Composition chimique des acides téichoiques isolés des fractions non dialysables obtenues après traitement enzymatioue des parois de B. megaterium KM

Les résultats des différents dosages, à l'exclusion du polyol dont la teneur n'a pas été déterminée, sont consignés dans le Tableau III et exprimés par unité de phosphore. Les teneurs renseignées en glucose sont celles obtenues par la méthode enzymatique et doivent être corrigées par un facteur compris entre I.3 et I.5 (voir MÉTHODEs). L'acide téichoique isolé de la fraction $\mathrm{KM} \cdot \mathrm{Lys} \cdot \mathrm{ND}$ a la composition suivante: phosphore $e_{1}$ glucose $e_{2-2 \cdot 3} \cdot \mathrm{N}$-acetylglucosamine ${ }_{1 \cdot 91} \cdot$ acide $\mathrm{N}$-acétylmuramique $_{1 \cdot 40} \cdot$ glycine $_{1 \cdot 69} \cdot$ acide $\alpha, \mathcal{E}$-diaminopimélique ${ }_{1 \cdot 6} \cdot$ alarine $_{2 \cdot 85} \cdot$ disaccharide AG-AAM $0_{0 \cdot 40}$.

Les acides téichoiques isolés des autres fractions non dialysables présentent une proportion $\mathrm{P} /$ glucose $/ \mathrm{N}$-acétylglucosamine identique à la précédente. Par contre, leur teneur en acide $\mathrm{N}$-acétylmuramique, en disaccharide $\mathrm{AG}-\mathrm{AAM}$ et en acides aminés est environ 4.5 fois plus petite lorsqu'ils ont été isolés des fractions obtenues par action de la préparation $\mathrm{F}_{\mathrm{I}}$ et $\mathrm{I} 3$ fois plus petite lorsqu'ils ont été isolés des frac: ions obtenues par action de la préparation $\mathrm{F}_{2} \mathrm{~B}$.

TABLEAU III

COMPOSITION CHIMIQUE RELATIVE DES COMPLEXES SCHIFF POSITIFS ISOLES DES

DIVERSES FRACTIONS NON DIALYSABLES OBTENUES PAR HYDROLYSE ENZYMATIQUE DES PAROIS DE B. megaterium $\mathrm{KM}$

$\mathrm{P}$, phosphore; $\mathrm{AG}, \mathrm{N}$-acétylglucosamine; $\mathrm{A} A \mathrm{M}$, acide $\mathrm{N}$-acétylmuramique.

\begin{tabular}{|c|c|c|c|c|c|c|c|}
\hline Fractions & $P$ & Glucose & $\begin{array}{l}\text { Disaccharide } \\
\qquad A G-A A M\end{array}$ & $A G^{\star *}$ & $A A M^{\star \star}$ & $\begin{array}{l}\text { Ac. glutamique } \\
\text { acide diaminopi- } \\
\text { mélique }\end{array}$ & Alaninc \\
\hline $\mathrm{KM} \cdot \mathrm{L}_{y s} \cdot \mathrm{ND}$ & 1 & 1.50 & 0.40 & $I .91$ & $\mathrm{I} .40$ & 1.60 & 2.85 \\
\hline $\mathrm{KM} \cdot \mathrm{F}_{1} \cdot \mathrm{ND}$ & 1 & $\mathrm{~T} .40$ & 0.09 & 1.31 & 0.28 & 0.33 & 0.54 \\
\hline $\mathrm{KM} \cdot \mathrm{Lys}_{\mathrm{y}} \cdot \mathrm{ND} ; \mathrm{FI}_{\mathrm{I}} \cdot \mathrm{ND}$ & $\mathbf{I}$ & 1.50 & 0.15 & 2.50 & $0.3^{\circ}$ & 0.40 & 0.69 \\
\hline $\mathrm{KM} \cdot \mathrm{F}_{2} \mathrm{~B} \cdot \mathrm{ND}$ & $\mathbf{I}$ & 1.52 & 0.04 & 1.63 & O. I I & 0.10 & $0.2 \mathrm{I}$ \\
\hline $\begin{array}{l}\mathrm{KM} \cdot \mathrm{Lys} \cdot \mathrm{ND} ; \mathrm{F} 2 \mathrm{~B} \cdot \mathrm{ND} \\
\mathrm{KM} \cdot \mathrm{Lys} \cdot \mathrm{ND} ;\end{array}$ & $\mathrm{I}$ & 1.87 & 0.06 & 1.80 & O. IO & - & 0.20 \\
\hline $\mathrm{F}_{2} \mathrm{~B} \cdot \mathrm{ND} ; \mathrm{F}_{1} \cdot \mathrm{ND}$ & I & I. 50 & 0.04 & 1.94 & O. IO & - & 0.17 \\
\hline
\end{tabular}

* Dosé par la glucose oxydase.

* Soustraction faite de la quantité contenue dans le disaccharide AG-AAM. 


\section{Sensibilité enzymatique de l'acide téichoique isolé de la fraction KM Lys $\cdot N D$}

L'examen électrorhéophorétique des acides téichoiques isolés des diverses fractions non dialysables (Figs. 4 et 5), leur comportement vis-à-vis de la ninhydrine et du réactif des $\mathrm{N}$-acétylhexosamines (Figs. 4 et 5 ) et enfin leur composition chimique respective (Tableau III) démontrent que l'acide téichoique isolé de la fraction KM. Lys $\cdot \mathrm{ND}$ est associé à des résidus mucopeptidiques. Au contraire, les acides téichoiques isolés des autres fractions en sont complètement ou presque complètement débarrassés, à la suite probablement du traitement par $\mathrm{F}_{1}$ et/ou $\mathrm{F}_{2} \mathrm{~B}$.

Cette hypothèse a été vérifiée en traitant par $F_{1}$ ou par $F_{2} B$ des aliquots de $200 \mu \mathrm{g}$ de l'acide téichoique isolé de la fraction KM·Lys $\mathrm{KD}$. Après une incubation de $\mathrm{I} 6 \mathrm{~h}$, les mélanges ont été soumis à une électrorhéophorèse à $\mathrm{pH} 4$ (dépôt au centre du papier; $20 \mathrm{~V} / \mathrm{cm} ; 4 \mathrm{~h}$ ) ou à une chromatographie en butanol acétique. On a ainsi observé que $F_{1}$ ou $F_{2} B$ dissocient effectivement ce complexe en: (a) une fraction hétérogène, Schiff négative, mais toujours sensible à la ninhydrine et au réactif des $\mathrm{N}$-acétylhexosamines, et chargée plus positivement que le complexe original; (b) une substance à migration homogìne, Schiff positive, insensible au réactif des $\mathrm{N}$ acétylhexosamines et chargée plus négativement que la substance originale. Sa sensibilité à la ninhydrine est très faible après incubation avec FI et nulle après incubation avec $F_{2} B$. Sa vitesse de migration est indépendante de la nature de l'enzyme utilisé et est identique à celle des substances Schiff positives isolées des fractions non dialysables autres que la fraction KM. Lys $\cdot \mathrm{ND}$ (Fig. 5).

De plus, la chromatographie, après incubation par $\mathrm{F}_{2} \mathrm{~B}$, a permis de détecter le disaccharide AG-AAM à l'état libre. Celui-ci a été estimé après élution d'un chromatogramme non révélé et représente environ $65 \%$ de la quantité totale de disaccharide directement dosée à partir du complexe original.

L'ensemble des résultats précédents permet donc d'attribuer au complexe téichoique-mucopeptide isolé de la fraction KM-Lys $\cdot \mathrm{ND}$, la constitution suivante, abstraction faite des proportions des constituants et de leur séquence dans les divers fragments considérés:

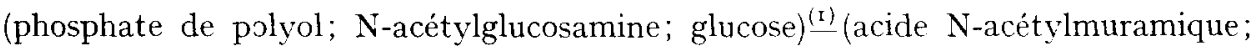
peptide) $\stackrel{(2)}{\longrightarrow}$ (disaccharide $\mathrm{AG}-\mathrm{AAM}$ ).

La liaison ( $\mathrm{I}$ ) est sensible à un enzyme commun aux préparations FI et F2B. Si les parois bactériennes sont directement traitées par l'une ou l'autre de ces préparations, le fragment constitué de phosphate de polyol, de $\mathrm{N}$-acétylglucosamine et de glucose peut être décelé dans les fractions non dialysables correspondantes, pratiquement dépourvu de tout résidu mucopeptidique.

La liaison (2) est sensible à un second enzyme également présent dans la préparation $\mathrm{F} 2 \mathrm{~B}$ (mais absent de la préparation $\mathrm{FI}_{\mathrm{I}}$ ). Il est sans doute identifiable à l'amidase précédemment décrite ${ }^{6,8}$. Le disaccharide AG-AAM est donc nécessairement en position terminale, uni au résidu peptidique par une liaison amidique entre la fonction $\mathrm{COOH}$ de l'acide $\mathrm{N}$-acétylmuramique et une fonction $\alpha-\mathrm{NH}_{2}$ (probablement de l'alanine ${ }^{8}$ ) du peptide.

\section{Hydrolyse acide partielle}

Afin de préciser si possible certains détails structuraux des complexes téichoiques étudiés et en particulier, la position relative du glucose et des deux $\mathrm{N}$-acétylhexos- 
amines (autres que celles qui forment le disaccharide AG-AAM), un certain nombre de fragments libérés par hydrolyse acide partielle de la fraction $\mathrm{KM} \cdot$ Lys.ND ont ćté isolés et caractérisés. Une hydrolyse de $15 \mathrm{~min}$ au bain-marie bouillarıt en présence de $\mathrm{HCl} 2 N(2 \mathrm{mg} / \mathrm{ml})$ a été adoptée. En effet, $50 \%$ environ du glucose présent dans les parois intactes sont libérés dans ces conditions. De plus, l'application des tests des hexosamines et des $\mathrm{N}$-acétylhexosamines sur les électrorhéophoréogrammes réalisés à partir de ces hydrolysats montrent que la déacétylation des $\mathrm{N}$-acétylhexosamines est négligeable.

L'hydrolysat de la préparation KM·Lys - ND a été séparé en trois fractions principales $\mathrm{N}, \mathrm{A} 2 \mathrm{O}$, et $\mathrm{A} 30$, en utilisant la technique déjà décrite (voir: Nature du polyol responsable de la réaction do Schiff et Tableau II). Il a été démontré que la fraction $\mathrm{A}_{\mathbf{3 0}}$ est uniquement constituée de phosphate de polyol. Le contenu des deux autres fractions a été analysé en chromatographiant des aliquots, correspondant environ à $8 \mathrm{mg}$ de la fraction $\mathrm{KM} \cdot \mathrm{Lys} \cdot \mathrm{ND}$, selon deux dimensions et chaque fois par méthode descendante, d'abord en butanol acétique, puis en n-butanol-pyridine-eau (6:4:1, $\mathrm{v} / \mathrm{v} / \mathrm{v})$ (Fig. 6 et Tableau IV).

Cinq substances ( $\mathrm{I}$ à $V$ ) ont été décelées dans la fraction $\mathrm{N}$ et deux substances (A et $\mathrm{B}$ ) dans la fraction $\mathrm{A}_{\mathbf{2 0}}$. Eluées à partir de chromatogrammes identiques mais non révélés, elles ont été identifiées soit par cochromatographie avec des standards de référence, soit en examinant, par les procédés de dosage et de chromatographie appropriés, les produits résultant d'une hydrolyse acide supplémentaire.

Outre le glucose (III), la N-acétylglucosamine (IV) et l'acide $\mathrm{N}$-acétylmuramique (B), divers complexes ont été mis en évidence.

Le complexe I, insensible à la glucose oxydase avant son hydrolyse est un polymère constitué de glucose uniquement. Sa coloration en gris brun par la diphénylamine-trichloracétique, de même que des cochromatographies avec le cellobiose, le maltose et le mélizitose ont montré qu'il s'agirait d'un tri-glucose plutôt que d'un glucosidoglucose.

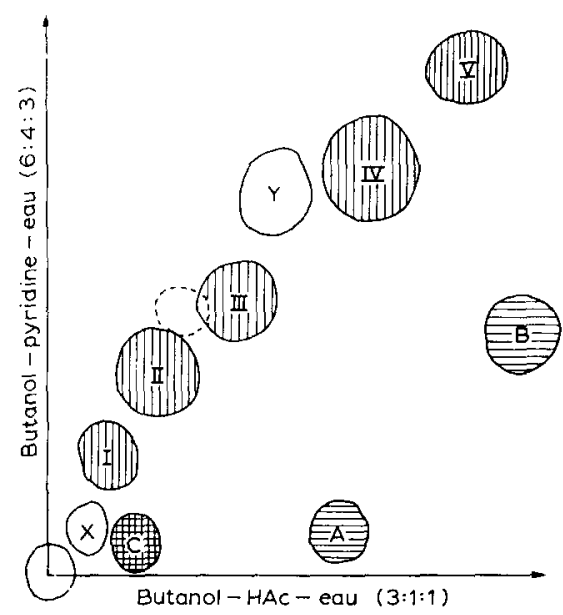

Fig. 6. Hydrolyse acide partielle des parois cellulaires de $B$. megaterium KM. Schéma des chromatogrammes obtenus à partir des fractions $N$ (substances $I$ à V), A2o (substances $A$ et $B$ ) et $A 30$ (substance $C$ ). X et $Y$, substances supplémentaires décelées dans l'hydrolysat partiel des acides téichoiques purifiés et soumis à la chromatographie sans fractionnement préalable. 
TABLEAU IV

HYDROLYSE ACIDE PARTIELLE DES PAROIS CELlULAIRES DE B. megaterium $\mathrm{KM}$

Colorations et composition qualitative des substances isolées par chromatographie. AG, N-acétylglucosamine; AAM, acide $\mathrm{N}$-acétylmuramique; PDAMB, réactif des $\mathrm{N}$-acétylhexosamines selon SALTON ${ }^{10}$.

\begin{tabular}{|c|c|c|c|c|c|}
\hline \multirow[b]{2}{*}{ Substancc } & \multicolumn{4}{|c|}{ Colorations } & \multirow[b]{2}{*}{ Composition } \\
\hline & $P D A M B$ & $\begin{array}{l}\text { Glucose } \\
\text { oxydase }\end{array}$ & $\begin{array}{l}\text { Diphenylamine- } \\
\text { trichloracétique }\end{array}$ & Schiff & \\
\hline \multicolumn{6}{|l|}{ Fraction $\mathrm{N}$} \\
\hline I & — & - & Gris-brun & + & Oligoglucose \\
\hline II & + & - & - & $t$ & Oligoglucose-AG \\
\hline III & $\ldots$ & ++ & Gris-brun & + & Glucose \\
\hline IV & ++ & — & Gris-verdâtre & + & $\mathrm{AG}$ \\
\hline $\mathrm{V}$ & + & - & Gris-brun (trace) & & Glucose-AAM \\
\hline \multicolumn{6}{|l|}{ Fraction A 20} \\
\hline A & + & - & - $^{*}$ & & Glucose-AAM \\
\hline$B$ & ++ & - & Rose & & $\mathrm{AAM}$ \\
\hline \multicolumn{6}{|l|}{ Fraction $\mathrm{A}_{30}$} \\
\hline C & - & 一 & - & $t+$ & Phosphate de polyol \\
\hline \multicolumn{6}{|c|}{$\begin{array}{l}\text { Hydrolysat partiel du } \\
\text { complexe téichoique purifié }\end{array}$} \\
\hline $\mathrm{X}$ & & 一 & Rose & & $?$ \\
\hline$Y$ & + & - & - & & (Glucose-AG)? \\
\hline
\end{tabular}

* Coloré en rose sur les chromatogrammes réalisés à partir des hydrolysats acides partiels de $2 \mathrm{mg}$ des complexes teichoiques purifiés.

Le complexe II est constitué de glucose et de $\mathrm{N}$-acétylglucosamine. Les proportions relatives ont varié, selon les analyses, de 2-3 glucoses pour I N-acétylglucosamine.

Les complexes $\mathrm{V}$ et $\mathrm{A}$ sont des disaccharides l'un et l'autre composés de glucose et d'acide $\mathrm{N}$-acétylmuramique (ou d'une substance donnant par hydrolyse acide, une hexosamine dont les propriétés chromatographiques sont identiques à celles de l'acide muramique) et ne peuvent être distinguées du point de vue de leur composition chimique globale. Cependant, le complexe $\mathrm{V}$ est une substance neutre à $\mathrm{pH} 5.5$, tandis que le complexe A est acide à ce $\mathrm{pH}$, ce qui semble d'ailleurs confirmé par leur $R_{F}$ respectivement élevé et nul en butanol-pyridine. La fonction $\mathrm{COOH}$ de l'acide $\mathrm{N}$-acétylmuramique serait donc bloquée dans le complexe V. Si ce blocage n'est pas dû à la présence d'une substance basique non décelée à l'analyse, glucose et acide $\mathrm{N}$-acétylmuramique doivent dans ce complexe être unis par une liaison ester. Enfin, le complexe $\mathrm{V}$, contrairement au complexe acide $\mathrm{A}$, n'est pas coloré en rose par la diphénylaminetrichloracétique. Il donne avec ce réactif une faible coloration gris-brune qui serait plutôt due à son résidu glucosidique que N-acétylmuramique.

Parmi les substances et les complexes libérés par hydrolyse ménagée de la fraction $\mathrm{KM} \cdot \mathrm{Lys} \cdot \mathrm{ND}$, quels sont ceux qui proviennent de l'hydrolyse du "fragment" téichoique qu'elle contient?

$2 \mathrm{mg}$ d'acides téichoiques purifiés (isolés de fractions non dialysables ayant subi une incubation avec $\mathrm{F}_{2} \mathrm{~B}$, supplémentairement ou non à une action du lysozyme et/ou de FI) ont subi la même hydrolyse partielle que la fraction $\mathrm{KM} \cdot \mathrm{Lys} \cdot \mathrm{ND}$, puis, sans aucun fractionnement préalable, ont été soumis directement à la chromatographie 
bidimensionnelle en butanol-acétique et butanol-pyridine. Les chromatogrammes ainsi obtenus témoignent de la présence de la plupart des substances et complexes identifiés dans les trois fractions $\mathrm{N}, \mathrm{A}_{20}$, et $\mathrm{A}_{30}$. Seuls l'acide $\mathrm{N}$-acétylmuramique libre (B) et l'oligoglucose (I) ne sont plus décelables. Semblablement, le complexe oligoglucose$\mathrm{N}$-acétylglucosamine (II) semble n'être présent qu'en faible quantité. Inversement, deux substances nouvelles ont été décelées. L'une, Y, est située entre le glucose et la $\mathrm{N}$-acétylglucosamine. Elle n'est pas colorée en rose par la diphénylamine-trichloracétique mais est sensible au réactif des $\mathrm{N}$-acétylhexosamines. Sa localisation même sur les chromatogrammes suggère qu'il s'agit peut-être du disaccharide glucose-Nacétyl-glucosamine. L'autre, $\mathrm{X}$, colorée en rose par la diphénylamine-trichloracétique et située près de l'origine peut vraisemblablement être considérée comme un produit d'hydrolyse encore très incomplète.

\section{JISCUSSION}

D’après les travaux récents de Salton et Ghuysen 7 , de Salton ${ }^{20}$ et de Ghursen ${ }^{6-8}$, la structure de base des parois de Micrococcus lysodeikticus peut être représentée par un réseau de troncs poly- $\mathrm{N}$-acétylhexosaminiques, auxquels sont associés des résidus peptidiques dont la taille et la séquence en acides aminés sont variables. Certains de ces résidus sont libres tandis que d'autres forment des ponts entre deux troncs polysaccharidiques voisins.

L'acide téichoique, non extractible à l'acide trichloracétique froid et présent dans les parois de $B$. megaterium KM, est combiné par liaisons covalentes à la structure de base de ces parois. Il peut être corisidéré comme un polymère de phosphates de polyol auquel sont associés de petits résidus constitués de glucose, de N-acétylhexosamines et d'acides aminés. Ce complexe téichoique-mucopeptide est uni à la structure de base de la parois bactérienne par l'intermédiaire d'une liaison amidique entre un $\mathrm{N}$-terminal de certains de ses résidus peptidiques et la fonction $\mathrm{COOH}$ d'un acide muramique d'un tronc poly-N-acétylhexosaminique.

En incubant les parois de $M$. lysodeikticus avec le lysozyme, on libère ${ }^{6,8}$ certains fragments disaccharidiques $A G$-AAM, toujours associés à des résidus peptidiques libres, ou encore des complexes constitués de deux fragments AG-AAM, supposés avoir appartenu à deux troncs poly-N-acétylhexosaminiques voisins, et toujours unis entre eux par un pont peptidique.

De même, en incubant les parois de B. megaterium KM avec le lysozyme, on libère des fragments disaccharidiques AG-AAM encore porteurs de tout le complexe téichoique-mucopeptide.

Le complexe téichoique-mucopeptide libéré des parois de B. megaterium KM par le lysozyme a un poids moléculaire minimal d'environ 2200 (le polyol étant supposé être du ribitol). Il contient $16 \%$ de glucose et $1.4 \%$ de phosphore. Comme la teneur en phosphore de la fraction dont il a été isolé (fraction $\mathrm{KM} \cdot \mathrm{Lys} \cdot \mathrm{ND}$ ) est de $0.775 \%$, il représente, en poids, environ $55 \%$ de cette fraction et $40 \%$ des parois bactériennes.

La sensibilité du complexe téichoique-mucopeptide à deux enzymes de Streptomyces (l'amidase de la préparation $\mathrm{F} 2 \mathrm{~B}$ et un second enzyme présent à la fois dans la préparation $\mathrm{F}_{\mathrm{I}}$ et $\mathrm{F}_{2} \mathrm{~B}$ ) permet d'y distinguer trois fragments principaux. Ils sont respectivement constitués de phosphate de polyol, de glucose et de $\mathrm{N}$-acétylglucosaamine (fragment téichoique), d'acide $\mathrm{N}$-acétylmuramique et d'acides aminés (fragment 
mucopeptide) et enfin du disaccharide AG-AAM (représentant un reste d'un tronc poly-N-acétylhexosaminique du mucopeptide de base).

La fréquence avec laquelle ce type de complexe téichoique-mucopeptide est présent dans les parois bactériennes, intimement combiné à la structure de base de celles-ci, n'a pas été recherchée. Cependant, l'acide trichloracétique froid n'extrait jamais qu'une fraction des acides téichoiques totaux de la paroi bactérienne. Selon SALTON $^{23}$, un traitement par l'acide trichloracétique, à $100^{\circ}$, pendant Io min, extrait pratiquement tout l'acide téichoique présent dans les parois de Staphylococcus aureus et de Lactobacillus arabinosus. Mais les dosages des fonctions $\mathrm{COOH}$ et $\mathrm{NH}_{2}$ terminales présentes dans les résidus insolubles ainsi obtenus, montrent que ces conditions expérimentales provoquent une hydrolyse des parois bactériennes. Deux fractions d'acide téichoique pourraient donc exister dans les diverses parois bactériennes où des phosphates de polyol ont été décelés: une première fraction, étudiée par BaDdiLEY et al., associće par liaisons ioniques au reste de la paroi et extractible par l'acide trichloracétique froid; une seconde, combinée par liaisons covalentes au mucopeptide de base de la paroi avec lequel elle forme un complexe non dissocié par l'acide trichloracétique froid.

La présence de toute trace d'acide téichoique, associé par liaisons ioniques au mucopeptide de base, dans la préparation des parois de B. megaterium KM qui a été étudiée, ne peut d'ailleurs pas être absolument exclue. Les préparations FI et F2B libèrent en effet $78 \mu$ moles d'alanine libre à partir de I g de ces pal;ois, mais n'en libèrent plus lorsque celles-ci ont été traitées par l'acide trichloracétiçue dans les conditions décrites. SALTON ${ }^{20}$ a émis l'hypothèse que la prépara inon $\overline{\hat{F}} 2 \mathrm{~B}$ pourrait contenir un enzyme hydrolysant la liaison amino ester qui unit les résidus alanyles au glucose ou à la N-acétylglucosamine dans les acides téichoiques décrits par BADDILEY et al. Si cette hypothèse était vérifiée et en admettant que l'alanine libéré sous l'action de FI ou $\mathrm{F}_{2} \mathrm{~B}$ avait pour origine un acide téichoique identique à celui des parois de $B . s u b$ tilis ${ }^{2}$, le calcul montre que cet acide représenterait, en poids, moins de $4 \%$ des parois de B. megaterium KM.

La structure du complexe acide téichoique-mucopeptide isolé de la fraction nor dialysable obtenue après traitement par le lysozyme des parois de B. megaterium KM ne peut, à l'heure actuelle, qu'être esquissée. En particulier, elle dépend de la nature exacte du polyol et de l'interprétation à donner aux résultats d'hydrolyse acide partielle.

Après bydrolyse acide partielle de la fraction $\mathrm{KM} \cdot \mathrm{Lys} \cdot \mathrm{ND}$, quatre types de complexes, dans lesquels le glucose intervient, ont été isolés (Tableau IV). Un premier complexe est un oligoglucose. Il n'a pas été retrouvé dans l'hydrolysat des acides téichoiques purifiés. Or, les dosages indiquent que $8.8 \%$, en poids, de la fraction $\mathrm{KM} \cdot \mathrm{Lys} \cdot \mathrm{ND}$ sont constituées par du glucose non associé au complexe téichoique. Ce glucose extra-téichoique forme donc probablement dans les parois un polyglucose qui par hydrolyse acide ménagée donne naissance à l'oligoglucose décelé dans les chromatogrammes. Dans les autres types de complexes, le glucose est associé soit avec de la $\mathrm{N}$-acétylglucosamine, soit avec de l'acide $\mathrm{N}$-acétylmuramique. Ceci suggère que des complexes de $\mathrm{N}$-acétylglucosamine, de glucose et d'acide $\mathrm{N}$-acétylmuramique existent, dans lesquelles le glucose occupe une position intermédiaire aux deux $\mathrm{N}$ acétylhexosamines. Enfin, deux types de liaisons glucose-acide N-acétylmuramique semblent possibles. L'une, glycosidique, laisserait la fonction $\mathrm{COOH}$ libre. L'autre, ester, bloquerait cette fonction, rendant ainsi le complexe neutre à tout $\mathrm{pH}$. 
L'un et l'autre de ces complexes glucose-acide $\mathrm{N}$-acétylmuramique ont été retrouvés après l'hydrolyse acide partielle des fragments téichoiques (débarrassés de leurs résidus mucopeptidiques par action des préparations FI et F2B). Or, il est certain que par ce traitement, la majeure partie de l'acide $\mathrm{N}$-acétylmuramique a été éliminée en même temps que les résidus: peptide-(AG-AAM) (Tableau III, Fig. 5). Il est donc difficile de préciser la nature de la liaison sensible à l'enzyme commun aux préparations Fi et F2B. Deux possibilités peuvent être envisagées. A chacune correspond un schéma structurel du complexe téichoique-mucopeptide. Ces schémas sont donnés dans la Fig. 7. Ils ont été construits en admettant que le polyol est du ribitol et en se basant sur la teneur relative des divers constituants du complexe téichoiquemucopeptide (Tableau III). Selon le schéma I, l'enzyme serait une estérase ou une glycosidase active sur la liaison Gluc-(AAM-peptide). Dans ces conditions, acide $\mathrm{N}$-acétylmuramique et peptide seraient unis par une liaison $\alpha$ amino ester ou amidique.

Schéma I.

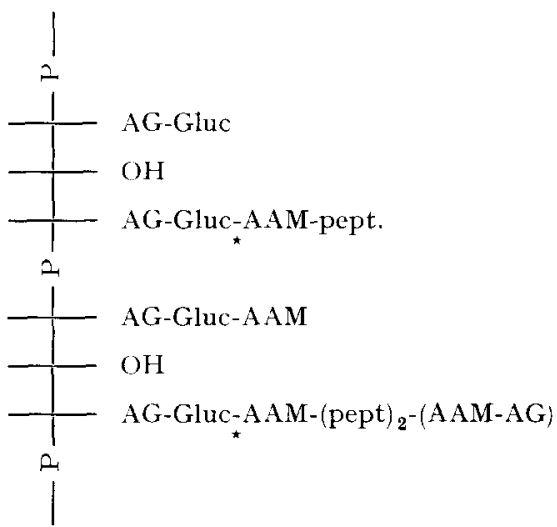

Schéma 2.

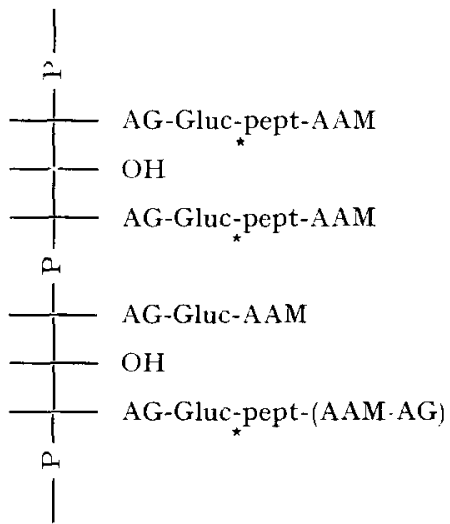

Fig. 7. Esquisses de la structure possible du complexe "acide téichoique-mucopeptide" libéré des parois cellulaires de $B$. megaterium KM par traitement au lysozyme*.

Selon le schéma 2 , l'enzyme serait une $\alpha$-amino estérase active sur la liaison Glucpeptide, celui-ci étant combiné, soit au disaccharide AG-AAM, soit à un reste N-acétylmuramique.

Dans l'un ou l'autre cas, la chaîne de phosphate de polyol porterait un petit nombre de résidus AG-Gluc-AAM. Ces résidus seraient insensibles à l'enzyme commun aux préparations $F_{I}$ et $F_{2} B$. Ils seraient responsables de la présence des disaccharides, neutre et acide, Gluc-AAM décelés dans l'hydrolysat acide partiel de la fraction KM. Lys·ND et des "fragments" téichoiques purifiés.

\section{REMERCIEMENT}

L'Auteur est Associé du Fonds National de la Recherche Scientifique de Belgique.

${ }^{*}$ Liaison sensible à un enzyme commun à $F_{2} B$ et à $F_{1}$, mais distinct de l'amidase de $F_{2} B_{\text {et }}$ de la N-acétylhexosaminidase de FI. Gluc, glucose; AG, N-acétylglucosamine; AAM, acide N-acétylmuramique; pept:acide glutamique ${ }_{1}$ :acide $\alpha, \varepsilon$-diaminopimélique : $_{1}$ alanine ${ }_{2}$. La composition globale du complexe est $P_{1}$-ribitol-Gluc ${ }_{2}-A_{2}-A_{A M_{1.5}}-$ pept $_{1 \cdot 5}-A G-A A M_{0.5}$. 
RÉSUMÉ

Les phosphates de polyol présents dans une préparation de parois de Bacillus megaterium KM ne sont pas extraits par l'acide trichloracétique froid, contrairement aux acides téichoiques décrits par BADDILEY et al.

Ils ont été isolés par électrorhéophorèse de la fraction non dialysable obtenue après incubation des parois avec le lysozyme.

Leur analyse montre qu'ils sont combinés à des résidus mucopeptidiques. L'ensemble du complexe représente environ $40 \%$ en poids des parois.

La dégradation de ce complexe par deux enzymes sécrétés par certains streptomycètes permet d'y distinguer trois fragments constitués de phosphate de polyol, glucose, $\mathrm{N}$-acétylglucosamine (fragment téichoique), d'acides aminés et d'acide $\mathrm{N}$ acétylmuramique (fragment mucopeptidique), du dissaccharide: acide $6-\mathrm{O}-\beta-\mathrm{N}-$ acétylglucosaminyle-N-acétylmuramique (fragment représentant un reste d'une chaîne poly-N-acétylhexosaminique du mucopeptide de base de la paroi).

Le fragment téichoique est libéré sous l'action des préparations, FI ou F2B, d'exoenzymes de Streptomyces. Il peut être obtenu en incubant directement les parois par ces préparations. Le fragment disaccharidique est libéré sous l'action de l'amidase contenue dans la préparation $\mathrm{F} 2 \mathrm{~B}$.

$6 \%$ environ, en poids, des parois sont constitués de glucose (probablement un polyglucose) étranger au complexe téichoique-mucopeptide étudié.

L'acide $\mathrm{N}$-acétylmuramique et divers oligosaccharides composés soit de $\mathrm{N}$-acétylglucosamine soit de $\mathrm{N}$-acétylglucosamine et d'acide $\mathrm{N}$-acétylmuramique, donnent, sur papier, une coloration rose par la diphénylamine-trichloracétique qui permet de les différencier de la $\mathrm{N}$-acétylglucosamine.

\section{BIBLIOGRAPHIE}

1 J. Baddiley, Proc. Chem. Soc., London, (1959) I77.

2 J. J. Armstrong, J. Baddiley et G. Buchanan, Biochem. J., 76 (1960) 610.

3 M. R. J. Salton et R. W. Horne, Biochim. Biophys. Acta, 7 (195I) 177.

4 J. M. Ghuysen, Arch. intern. physiol. et biochim., 65 (1957) I73.

5 J. M. Ghuysen et M. R. J. Salton, Biochim. Biophys. Acta, 40 (I960) 462.

6 J. M. Ghuysen, Biochim. Biophys. Acta, 40 (1960) 473.

7 M. R. J. Salton et J. M. Ghuysen, Biochim. Biophys. Acta, 45 (I960) 355.

8 J. M. Ghuysen, Biochim. Biophys. Acta, sous presse.

${ }^{9}$ S. M. Partridge Et R. G. Westall, Biochem. J., 42 (I948) $23^{8}$.

10 M. R. J. Salton, Biochim. Biophys. Acta, 34 (I959) 308.

11 L. Hough, J. K. N. Jones et W. H. Wadman, J. Chem. Soc., (I950) I 702.

12 J. G. Buchanan, C. A. Dekker et A. G. Long, J. Chem. Soc., (I950) 3 I62.

13 Spinco Division Beckman Instrum., Inc., Palo Alto California, Technic. Bull. no TB 6046 B, April I958.

14 M. R. J. Salton et J. G. Palvik, Biochim. Biophys. Acta, 39 (I960) 398.

15 E. J. KING, Biochem. J., 26 (1932) 292.

16 O. W. Neuhauer et M. Letzring, Anal. Chem., 29 (1957) 1230.

17 J. L. Reissig, J. L. Strominger et L. F. Leloir, J. Biol. Chem., 217 (I955) i959.

18 N. H. Wilson et W. C. Hughes, J. Soc. Chem. Ind., Japan, 58 (1939) 74.

19 E. A. McСомв Et R. M. MCCready, Anal. Chem., 29 (1957) 8 I9.

${ }^{20}$ M. R. J. Salton, Biochim. Biophys. Acta, sous presse. 